\section{GERMAN CONGRESS OF EXPERIMENTAL} PSYCHOLOGY.

THE second congress of the German Society for Experimental Psychology took place on April 18-21 in the picturesque old town of Würzburg, partly at the old university and partly at the well-known psychological laboratory of Prof. Külpe. Two visits were paid to Prof. Rieger's nerve hospital. The attendance amounted to nearly 200 , and thus was even more numerous than at the first congress two years previously in. Giessen. Prof. G. E. Müller was in the chair. Fewer papers were read than before, but nevertheless they could with difficulty be got through in the three and a half days available, reading eight hours a day.

A new feature in this congress-and one that indicates the rapid growth and advancing specialisation of experimental psychology - was that several members of the society had been commissioned to make general reports (Sammelreferate) on particular branches of research with which they were known to have an exhaustive acquaintance. Conspicuous among these reports was that of Külpe (Würzburg), on the general state of experimental æsthetics. The methods of experiment were grouped under three general heads, impression (Eindruck), formation (Herstellung), and expression (Ausdruck); each of these admitted of many further subdivisions. The interesting results communicated were mostly of American and very recent origin. In general, Külpe emphatically maintained that æsthetic values are not wholly of a subjective nature (Einfühlung, zuständlich, \&c.), but are to some degree at least objective (gegenständlich). The time was near, he said, when these experimental investigations would claim serious attention from both art critics and artists. ${ }^{2}$ Sommer (Giessen) gave a very interesting report on psychiatry and individual psychology, tracing back the modern close union and wonderful development of these two sciences to ideas which arose in the eighteenth century, as the natural sequel to the psychological researches of Descartes and, above all, Locke. The execution of these ideas has only been delayed until now for want of adequate methods. Sommer indicated the essentials of good methods of psycho-pathological investigation, particularly insisting upon the necessity of a uniform system of tests, thoroughly tried in normal, border, and distinctly pathological cases. Weygandt (Würzburg) presented a full report on the psychological examination of weak-minded children. Krueger (Leipzig) reported on the relation between phonetics and psychology. In the course of an exhaustive and lucid exposition of the previous methods and results, he showed that hitherto attention had Deen almost exclusively confined to the bare morphological elements of speech, as represented by the letters of the alphabet. He himself had chiefly investigated how one and the same syllable can be represented by very varying sounds, according to nationality, emotion, or shade of meaning; his graphic registrations of the modulations of voice as regards speed and pitch excited considerable interest among the audience. On a subsequent day Krueger gave a practical demonstration of his ingenious apparatus for registering the vibrations of the larynx (Kehltonschreiber), designed. by himself together with Wirth. Schumann (Zürich) gave a report on the psychology of reading. He described the remarkable success with which reading had been taught by whole words, instead of by single letters. A large portion of the paper dealt with tachistoscopy, and especially with the best means of exposing letters to view for very short periods of time; the difficulty is to prevent a persistent after-image, and the remedy recommended is to let the exposed letters be replaced, not by a blank surface, but by another arrangement of letters.

Turning to the exclusively original papers, a remarkable one was read by Stumpf (Berlin) on the " sensations of feeling " (Gefühlsempfindungen). The feeling (i.e. the pleasantness or unpleasantness) that characterises a sensation must be sharply distinguished, he finds, from the feeling characterising intellectual states. The former may be conceived in three ways: first, as a "feeling-tone" or mere quality of the sensation; secondly, as a peculiar element of consciousness, closely associated indeed with

$1 \mathrm{Külpe}$ 's paper will be somewhat amplified in the official account of the proceedings of the Congress. (Published by Barth, Leipzig.)

NO. I 906, VOL. 74] the sensation, but just as self-existent as the latter; and thirdly, as only another kind of sensation in addition to, and independent of, those of touch, sight, sound, taste, and smell. He expounded the grounds which had now at last compelled him to adopt the third alternative. The paper found warm appreciation, but very little acquiescence. Dürr (Würzburg) had, by means of reaction experiments, investigated voluntary action and association. These two had proved themselves perfectly different from one another; the former was either a making distinct. (Verdeutlichung) or else a production (Produktionserfolg); the latter was a reproduction (Reproduktionserfolg). Further, his results were in flat contradiction to the popular theory that the ultimately victorious motive must be the one accompanied by the idea of greatest pleasure or least pain. At the same time, he attributed little causal importance to the consciousness of self (Ichbewusstsein). In harmony with his results was a notable experimental investigation of the will by Ach (Marburg). Here too reaction experiments were used, but cleverly devised so that the force of the will and that of association acted in direct opposition to one another. By this means the manifestations of the two forces could be vividly contrasted, and even subjected to a certain degree of measurement. Ach, like Dürr, finds the pleasure-pain theory to be totally discordant with actual observation. Bühler (Würzburg) discussed the experimental analysis of complicated processes of thought. Each of his observers had had to reply to a series of questions, and at the same time to observe carefully the mental process thereby involved. The result had been to corroborate the statement of Ach and Binet, that the real elements of thought are not faint presentations (verblasste Vorstellungen), but ideas (Bewusstheiten). Messer (Giessen), in his experimental psychological investigation of thought (again by means of reaction experiments), had been able to detect and observe the process of "judgment" as a specific conscious experience. He admitted that this was only possible under certain very favourable conditions, and to this cause he attributed the fact that the experiments of Marbe had resulted in a denial of any such specific experience.

Wirth (Leipzig) dealt with the distribution of attention in different senses (sight, sound, and touch). The allotted three-quarters of an hour barely sufficed for enumerating swiftly the chief features of his wonderfully skilful and complicated mechanical arrangements. Of his rich harvest of psychological results he had only time left to exhibit some numerical tables, showing that all parts of each sensory field presented a regular gradation of sensibility, the maximum of which lay wherever the attention happened to be focused. Fortunately, this research will very soon find more adequate expression in print (Psycholog. Studien, ii., 2). Unexpected results had been obtained by Specht (Leipzig) concerning the divergence of the relative and absolute thresholds of sensibility under the influence of alcohol; though the power of discriminating between two sounds of different intensity is much weakened by alcohol, the power of hearing a sound at all is actually increased by it. Rupp (Göttingen) had analysed. (by reaction experiments) the localisation of touch stimuli on the fingers into two distinct processes: the localisation of the sensation in space, and its attribution to a particular finger. The former process was the quicker one. By means of certain unusual postures the two processes could be brought to give contradictory indications; thereupon the reaction-time was always lengthened, and sometimes the sensation was even attributed to the wrong finger. Linke (Naumburg) showed by his new stroboscopical experiments that stroboscopical effect is not wholly due to after-images, but also in large measure to causes of a more intellectual nature. The investigation by Veraguth (Zürich) of the galvanic psychophysical reflex had revealed that mental excitement has a marked effect on an electric current passing through any part of the body; but Sommer explained that these electric phenomena were of a secondary character, arising from changes of pressure and sweat-excretion. Marbe (Frankfort) exhibited an ingenious, practical, and comparatively inexpensive experimental arrangement for brief optical stimuli; a ray of light of any desired briefness, intensity, or colour is projected beside another similar but continuant ray. Ebbing- 
haus demonstrated his new, but already widely adopted, fall apparatus for the control of chronoscopes and other timemeasuring instruments (for full description, see Zeitschr. f. Psychologie, xxx., 292). Several other apparatus were exhibited, but unfortunately not in such rich variety as at Giessen.

The other papers were those of Jerusalem (Vienna), on remembering and forgetting; Witasek (Gratz), on the methodics of measuring memory; Pfeiffer (Würzburg), on a method of determining qualitative types in school-work; Lipmann (Berlin), on the effect of suggestive questions; Asher (Bern), on the law of the specific energies of the senses; Detlessen (Wismar), on colour-values and colour-measurement Hughes (Soden), on single affective states; Schultze (Würzburg), on accentual effects (Wirkungsakzente); Decroly (Brussels), on anthropometrical and psychological tests for children; v. Aster (Munich), on the third dimension of the spatial presentation (visual); and Kobylecki (Cracow), on psychological experiment without introspection.

On the whole, the congress showed itself strongly influenced by the universal and increasing reaction against the materialistic atomism of the early days of experimental psychology. The admission is ever gaining ground, that consciousness is something more than a mechanically changing conglomeration of sensations and feelings in varying quality, intensity and complication.

The earnest scientific tone and strict attention to business which had so favourably distinguished the Giessen congress from the international ones was on the present occasion even more marked. The members allowed themselves no relaxation until after the close of the proceedings, when a general picnic was made to the beautiful Veitshöchheim "Pleasure Palace" of the former PrinceBishops. The next congress will be held at Frankfort (on the Main) on April 22-25, 1908.

C. Spearman.

THE MILAN INTERNATIONAL EXHIBITION. THE Milan exhibition, which was opened in state by the King and Queen of Italy on April 28, is still far from complete. The reason for its unfinished condition is to be found in the increased scope of the exhibition. As originally planned, it was intended to commemorate the opening of the Simplon Tunnel by confining the exhibition to a display of progress in transport by land and water. Gradually other branches of industry were added, and support has been accorded by the leading European countries, France predominating with an area of 250 ,000 square feet. Austria follows with 180,000 square feet, Germany with 160,000 square feet, Belgium with 108,000 square feet, Great Britain with 75 ,0oo square feet, and Hungary with 32,000 square feet. The exhibition covers an area of 400 acres, of which more than half is covered by buildings of a decorative character. Italian exhibitors occupy about one-half of the space, and the exhibits afford striking evidence of the remarkable industrial progress that has been made in Italy of late years. Altogether the exhibition is exceptionally attractive from a popular and a business point of view, whilst from a technical point of view its chief interest is due to the fact that it is the first international exhibition in which electricity has been used for driving the machinery shown in operation.

Of the exhibits of scientific interest, the most interesting are those of the Italian Admiralty. The methods employed in the preparation of charts and the manufacture of torpedoes are well shown. The retrospective exhibition associated with the transportation section is also of great interest. The early history of navigation and of steam transport is illustrated in an admirable manner. Exhibits of historical interest are contributed by the Board of Education, the Corporation of London, Lloyd's Register, the Institutions of Civil and Mechanical Engineers, and the Iron and Steel Institute.

In the various international sections valuable prizes are offered by the King of Italy. They include $400 l$. for the best exhibit of machinery, $400 l$. for the best type of workman's dwelling, $400 l$. for the best flying machine, $400 l$. for the best motor omnibus, $200 l$. for automatic railway couplings, 20ol. for the best method of testing high-voltage electric currents, $200 l$. for motor-boats, and $200 l$. for the best motor-plough.

No. I 906 . voL. 74$]$

\section{UNIVERSITY AND EDUCATIONAL INTE LLIGENCE.}

OXFORD.-The University Alembic Club celebrated its hundredth meeting on Saturday, April 28 , by holding a dinner in the banqueting room of the Town Hall. The professor of chemistry, the Lee reader, and the Aldrichian demonstrator were present. All the past-presidents of the club and a number of old members attended.

The 283 rd meeting of the Junior Scientific Club was held on Friday, May, 4, when papers were read on "Bubbles and Emulsions," by Dr. W. Ramsden, and "Who were the Greeks?" by Mr. J. L. Myres.

Cambridge. - The council of the Senate has nominated Prof. Woodhead, Mr. A. Sedgwick, and Mr. A. E. Shipley, and the special board for biology and geology has nominated Prof. Langley, Mr. J. J. Lister, and Mr. F. F. Blackman, to be members of the board of managers of the Quick fund. The election to the Quick professorship of protozoology rests with the board of managers, who will also control the expenditure of the income derived from the bequest of the late Frederick James Quick.

Mr. F. G. Hopkins, of Emmanuel College, and $\mathrm{Mr}$ W. M. Fletcher, of Trinity College, have been elected examiners to the Gedge prize in physiology.

It is arranged that the voting on the proposals of the Studies and Examination Syndicate with reference to the doing away with compulsory Greek for mathematical and natural science students will take place on the afternoons of Friday, May 25, and Saturday, May 26.

Prof. Macalister, Prof. Langley, and Dr. Hill have published a time-table of courses in human anatomy, physiology, and histology to be held during the long vacation, beginning on July 4 .

In addition to the ordinary classes in general pathology and pharmacology to be given at the New Medical Schools during the long vacation, the series of shorter courses dealing with more advanced work will be repeated this year. These courses are open to medical men and senior students only.

A course of seven lectures on "The Morphology of the Bryophyta" was commenced by Prof. J. B. Farmer, F.R.S., at the Chelsea Physic Garden on Tuesday, May 8. Admission is free by ticket, obtainable on application to the Academic Registrar of the University of London.

A course of eight lectures on the "Structure and Functions of the Central Nervous System," with special reference to the brain stem, will be commenced in the physiology department of University College, London, by Dr. W. Page May, on Wednesday, May 16. The lectures are open to all students of the University of London, also to qualified medical men on presentation of their cards.

THE following benefactions to higher education in the United States are announced in Science:- - The University of California has received a gift of $20,000 l$. from the widow of the late Judge John H. Boalt. Mr. Andrew Carnegie has offered $8000 l$. to Denison University for a new library building on condition that a like sum is secured elsewhere for the endowment of the library. Through the generosity of Mr. Robert S. Brookings and Mr. Adolphus Busch, the medical department of Washington University (St. Louis) has received a gift of $10,000 l$.

AN earnest and well-informed plea for the provision of more adequate funds for the University of Cambridge is made in the current number of the Quarterly Review. Though it is a mistake to suppose that the flow of benefactions to the old universities has ceased entirely, the fact remains that Cambridge has twice appealed, once in 1898 and again in 1904, for help to meet her responsibilities. It is alleged that the demands of science have emptied the University chest, and yet there is a popular belief that the university of Newton and Charles Darwin, of Maxwell and Rayleigh, is still shrouded in mediæval shadow. When it is remembered that the expenditure on buildings devoted to science alone since 1862 must have exceeded $300,000 l$., and that other great expenses have been incurred in the same direction, it is not difficult to understand that it has been done only with external help, and that unless more 